\title{
Pontal do Paranapanema: planejamento territorial e conflitos de terras (1886-2011)
}

Dossier Rede URbana E Definição das Fronteiras Paulistas

\section{Luiz Augusto Maia Costa}

Filósofo [U.C. Salvador], Arquiteto e Urbanista [UFBA]. Mestre, Doutor e Pós-Doutor em Arquitetura e Urbanismo [USP]. Professor Titular do Programa de Pós-Graduação em Urbanismo e da Faculdade de Arquitetura e Urbanismo da PUC-Campinas. Campinas [SP] Brasil <luiz.augusto@puc-campinas.edu.br>.

\section{Resumo}

O presente artigo visa investigar as possíveis relações entre planejamento territorial, ocupação territorial e conflitos de terras na região do Pontal do Paranapanema. Para isso, retoma ao ano de 1890 quando o engenheiro Theodoro Sampaio faz o que seria o primeiro plano de ocupação da área conhecido e sugere que parte destas áreas fossem "reservas para o futuro".

\section{Palavras-chave / Palabras clave / Mots-clés / Parole chiave}

Planejamento territorial. Pontal do Paranapanema. São Paulo. Conflitos de terra.

\section{Pontal do Paranapanema [west Sao Paulo state, Brazil]: territorial planning and land conflicts (1886-2011)}

\begin{abstract}
The present article aims to investigate the possible relations between territorial planning, territorial occupation and land conflicts in the Pontal do Paranapanema region. To do this, it resumes in the year 1890 when engineer Theodoro Sampaio makes what would be the first plan of occupation of the known area and suggests that some of these areas were "reserves for the future".
\end{abstract}

\section{Keywords}

Territorial planning. Region of "Pontal do Paranapanema". State of Sao Paulo. Land conflicts. 


\section{Introdução}

Nos quatros primeiros séculos da experiência histórica do que entendemos hoje como o Brasil, São Paulo, a cidade como o território, exerceu um papel secundário tanto no âmbito nacional, como internacional. Essa situação começou a mudar, lentamente, a partir de 1850, e alcançou um ritmo frenético no nascer do século seguinte. As bases materiais disso já são bem conhecidas: café, ferrovia, a existência de um "complexo cafeeiro" que amalgamava as diversificadas e díspares atividades econômicas então engendradas, as quais, para se desenvolverem recriaram, transformaram e resignificaram a rede de cidades pré-existente conformando um vasto território o qual "desde sempre" foi chamado de paulista.

Parte dessa estratégia passava pelo desenvolvimento de certo planejamento, não nominado, que fora forjado no interstício da relação porosa, então existente, entre público e privado. Esse planejamento começou a ser cultivado, sobretudo, pela "intrigante" geração de 1870. Não está ainda muito claro como, nem porque, no último quartel do século dezoito, uma serie de atores sociais egressos da elite colonial/imperial paulista, passou a empreender um esforço, frouxamente articulado, em direção a uma nova ordem social - econômica que contribuiu para desembocar no fim da escravidão, no advento da República e, sobretudo, no "surgimento" de uma ordem burguesacapitalista no Brasil.

Em termos paulista, isto estava diretamente articulado com o reconhecimento e com a apropriação do seu espaço geográfico. No âmbito do estado, o território passou a ser redesenhado a partir da ocupação deste pelas fazendas de café, interligadas pelas ferrovias que cortavam o mesmo e redesenhava-o; pelo estabelecimento de uma nova rede de cidades, engendradas pela requalificação da rede já existente e pela criação de uma série de novas cidades. São Paulo constituía-se então como o nó centralizador e concentrador de toda essa rede. É assim que, na historiografia urbana da capital, aponta-se que foi na década de 1870, quando o governo da então Província de São Paulo, estava a cargo de João Teodoro Xavier de Matos, que se deu o primeiro surto urbanístico da capital. Um pouco depois, em 1886, agora não no âmbito do governo municipal e sim estadual, cria-se a Comissão Geográfica e Geológica da Província de São Paulo (CGGSP), instituição científica diretamente ligada às atividades do Complexo Cafeeiro e à produção do espaço construído do estado (Costa, 2003).

\section{Um Plano Territorial não nomeado para o Pontal do Paranapanema}

Em 1890, o engenheiro Theodoro Sampaio, então membro da Comissão Geográfica e Geológica de São Paulo, escreveu um alentado estudo sobre a região do extremo Oeste Paulista intitulado Considerações Geográficas e Econômicas sobre o Vale do Rio Paranapanema, o qual foi publicado no Boletim no 4 da referida Instituição, o mesmo é considero pelo engenheiro como um complemento ao "Relatório da Exploração dos rios Itapetinga e Paranapanema".

No escopo do aludido estudo discorre sobre temas que vão das condições climáticas da região até aspectos relativos às terras públicas, no que inclui uma seção referente ao "Vocábulo Caiuá". De particular interesse para os nossos atuais intuitos, é o item "Distribuição das Terras segundo a capacidade agrícola". Logo de imediato, Sampaio afirma que, segundo suas estimativas, o território do Vale do Paranapanema seria de $27.400 \mathrm{Km}^{2}$, estando o mesmo dividido em três regiões ou zona, a saber: da mata, dos campos e das terras altas, isto é, aquelas acima de $650 \mathrm{~m}$ de altitude.

Ao comentar a zona da mata, ao meio da descrição detalhada dela, acaba por expor claramente as melhores formas para explorar as potencialidades da sua terra roxa - cultivo do café - ao mesmo tempo em que critica a monocultura então empregada em longa escala no estado. Em seguida passa a fazer uma mesma descrição detalhada sobre a zona dos campos, procedendo igualmente com as terras altas. São sobre os comentários feitos acerca dos "campos" que gostaríamos de nos deter.

Sampaio identifica essa zona como sendo a de maior área dentro do Vale e então se pergunta se o mesmo será "acaso hoje e sempre um vastíssimo território apenas utilizável pela indústria pecuária?". Segundo o mesmo, a resposta a essa pergunta, "por parte dos entendidos", ainda estava suspensa. $\mathrm{Na}$ 
sequência, indaga se "a lavoura, porventura, poderá contar com os terrenos campestres como uma reserva do futuro". Conclui que sim. É então que afirma:

Os campos são na realidade reservas do futuro, serão um dia o teatro de uma lavoura mais inteligente e racional, quando o coeficiente da população relativa deixar de ser uma fração para se tornar o representativo de muitas dezenas de entes humanos por quilômetros quadrados do nosso território (Sampaio, 1890). Grifos nossos.

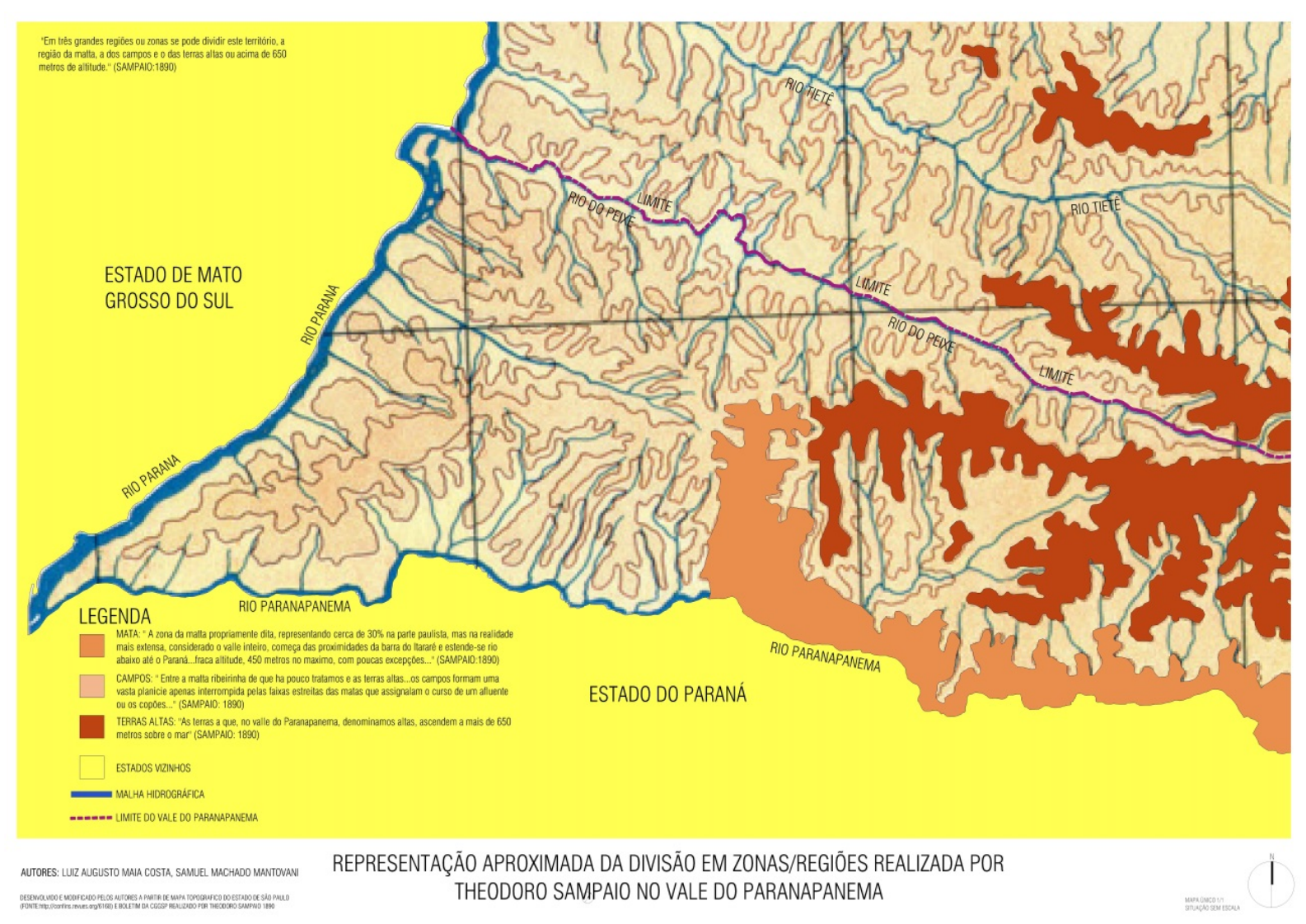

Figura 1. Mapa da área do Pontal do Paranapanema e o extremo Oeste Paulista.

Fonte: Costa, Montovani (2013). No mapa vemos a diferenciação das terras do Vale do Paranapanema concebida por Theodoro Sampaio em 1890 - em marrom, as Matas; em rosa, os campos e em vermelho as terras altas - e a delimitação do Pontal do Paranapanema (em lilás). Na confruência entre os rios Paraná e Paranapanema localizam-se alguns dos municípios que mais conflito de terras há hoje em dia no estado.

A partir deste momento, em uma perspectiva capitalista, indica o que deverá ser feito no futuro para viabilizar a ocupação do mesmo da maneira mais econômica possível. No bojo desse "plano" não nomeado como tal, acaba por expor toda a sua fé na tecnologia, na técnica e no desenvolvimento da sociedade por intermédio da ciência.

0 que nos chama a atenção aqui é que o seu discurso dá margens para o estabelecimento de um mercado para essas terras, sugerindo que, se naquele momento "os campos" não eram tão rentáveis, no futuro (quando?) seriam. Todas as melhorias por ele indicadas, indubitavelmente, tornariam essas terras ainda mais valorizadas. É razoável pensar que, nas entrelinhas, ele estava sugerindo que não as utilizasse naquele momento, guardando-as para o futuro; isto é, que as reservassem para utilizá-las quando elas tivessem alcançado maior poder de produção, maior valor. Se pensarmos em como essas terras eram obtidas - por meio da grilagem, logo por preços módicos, é lógico pensar que sua valorização ocorreria em projeções exponenciais; era uma questão de tempo. Ao longo do resto do texto, essa sensação de que se estava delineando um projeto futuro de ocupação da região se confirma. 
É assim que após findar as descrições físicas do Vale, passa a sua descrição humana. Da leitura detalhada desta seção, nos é possível entrever a visão que o engenheiro possuía da questão. Para Sampaio a ocupação da região foi realizada por brasileiros que enfrentaram o "índio inimigo". Logo, para Sampaio, o índio era um obstáculo à ocupação destas terras. Para ele, essa ocupação deveria se dar por migrantes brasileiros e não por imigrantes estrangeiros, os quais deveriam ir para as fazendas de café em terras já ocupadas. Daí ser razoável pensar que era o brasileiro e não o imigrante que deveria ser exposto ao "perigo". Nisso vai toda uma concepção do Estado no processo de colonização desta área e de como esse mesmo Estado compreendia o trabalho e o trabalhador.

Para Sampaio, o índio era um "outro" que o processo civilizatório iria tirar da condição de "selvagem". o papel social que o índio então civilizado, por meio da catequese, desempenharia não fica claro. 0 certo é que ao longo das páginas que se detêm a refletir sobre o tema, Sampaio, outra vez, procede do mesmo modo: identifica o problema e, depois, apresenta a solução que lhe parece a mais adequada. Se o problema para a ocupação destas terras é o índio, a solução é a catequese (e aqui, catequese está sendo utilizada pelo engenheiro quase como sinônimo de reserva indígena); ora podemos associar isso a um plano, cuja finalidade última era "preparar os terrenos" para a sua futura exploração econômica.

Se continuarmos acompanhando o raciocínio de Sampaio, iremos nos deparar com mais um aspecto relevante para a ocupação destas terras: a questão das terras públicas. Da leitura desta passagem do referido estudo depreende-se algumas observações interessantes. 0 modus operandi de tratar a questão é a mesma. Primeiro identifica-se o problema e logo após apresenta-se uma solução. Segundo o engenheiro, o problema era a especulação e/ou a ocupação imprópria das terras, sendo a solução a intervenção moderada do Estado. Neste caso, Sampaio ainda acrescenta uma terceira etapa do seu "plano" de ocupação do território, que consiste na viabilização do mesmo.

Para nós, à medida que a leitura destas Considerações avança, mais claro fica a intenção geral deste "relato" elaborado pelo engenheiro, vimos neste um claro delineamento de um planejamento territorial, no qual a ocupação das terras do Vale, com todas as suas implicações, faz-se notar: relação público versus privado, uso a ser dado a elas (baseados em princípios de "método e sistema"), valores que elas alcançariam, bem como os valores obtidos a partir delas, e por fim, os seu aspectos jurídicos.

Isso nos faz lembrar imediatamente dos Núcleos Coloniais, propostos por Domingos Jaguaribe na mesma época. Nessa perspectiva, não é estranho que as terras desse especulador tenham sido grafadas nos mapas do Relatório da Exploração dos Rios Itapetinga e Paranapanema, como também não é estranho que Domingos Jaguaribe seja apontado como um dos articuladores da criação da Comissão Geográfica e Geológica de São Paulo. É esse quadro geral que nos faz concordar com José Oswaldo Soares de Oliveira (1997) quando ele aponta que o trabalho empreendido por Jaguaribe deve ser entendido como um esforço de planejamento territorial do estado de São Paulo.

Chama ainda a atenção, o fato de, a despeito de não apoiar no corpo do texto que elabora a especulação de terras, nas entrelinhas do mesmo deixar brechas para ela. Nesse sentido, é interessante a correspondência entre Sampaio e Jaguaribe e, em particular, a obra de Sampaio Terras de propriedade do Dr. Domingos Jaguaribe (1898), na qual o engenheiro faz estudo detalhado das referidas fazendas discorrendo claramente sobre suas potencialidades. A maior propriedade de Domingos Jaguaribe situava-se no Vale do Paranapanema, às margens desse rio. Concluímos então que todas as outras considerações anteriormente apontadas como "planos" estão interligadas, conferindo um caráter de conjunto muito bem articulado que visa à ocupação do território; isto é, trata-se, indubitavelmente, de um planejamento territorial e esse planejamento se irradiaria para uma região mais ampla. Mais adiante retomaremos esse ponto.

Outro tópico abordado por Sampaio em suas Considerações é "Indústrias e Comércio". Após descrever as atividades econômicas já existentes na região, o engenheiro busca racionalizar o escoamento da produção da mesma. Para isso acentua a supremacia da Ferrovia Sorocabana como via de escoamento preferencial da produção, ao mesmo tempo em que demonstra o quanto o café é valorizado à medida que vai sendo transportado. 
Ao fazer isso ele explicita uma "segunda razão de ser" das ferrovias: além de transportar o café, elas o valorizam. Valorizadas são também as terras, desde que as ferrovias as cortem que sejam ocupadas e que, por fim, sejam cultivadas. Portanto, ele nomeia o que já se sabe: a infraestruturação das terras as valoriza. 0 que Sampaio está a dizer não é novidade. A novidade aqui é que tais procedimentos ficam, doravante, legitimados por um discurso e prática científica. Parece-nos ainda pertinente relembrar que a CGGSP é uma iniciativa política estadual e que a elite administrativa do Estado confundia-se intimamente com a elite econômica, isto é, a "burguesia agrária" — produtora de café; os empreendedores e industriais então emergentes.

Se até agora Theodoro Sampaio veio tecendo, de forma errática, uma série de observações e indicações de como deveria se dá a ocupação das terras do Vale, no item "Das comunicações Interiores pelo Vale do Paranapanema", ele explicitamente expõe seu plano para a área. De imediato ele escreve:

A posição do Vale do Paranapanema, em relação aos portos da costa ocidental do Brasil e a bacia hidrográfica do Paraná, de longa data, há chamado a atenção dos poderes públicos como oferecendo uma das boas soluções ao problema das comunicações interiores do país, especialmente para o remoto estado de Mato Grosso.

Afirma então que tal problema está posto desde o período colonial e que àquela época ainda encontrava-se sem uma solução definitiva. Expõe então, como entende a relação entre São Paulo e Mato Grosso, grosso modo, uma relação de dependência deste daquele. 0 grande obstáculo para selar essa relação de forma mais estreita é a questão das ligações internas entre estes dois estados. A chave do problema, para Sampaio, estava no sistema hídrico do estado de Mato Grosso. Segundo Sampaio (1890):

O problema das comunicações para Mato Grosso, só pode ser atendido pelo lado dos interesses da administração, do povoamento do território, ou para o caso eventual de uma guerra exterior. O problema assim considerado teria, pois, de preencher as seguintes condições:

1.Ser o quanto estratégico.

2. Exigir o menor dispêndio possível.

3. Aproveitar as estradas de ferro já construídas e os rios suscetíveis de navegação, de modo a oferecer sempre uma ligação entre a capital federal e aquele remoto Estado.

Dito isso, passa então a delinear seu plano, descrevendo detalhadamente o desenho que tais comunicações adquiririam. Para nossos intuitos imediatos, acreditamos que não sejam necessários maiores comentários além dos já feitos. O Plano está claramente posto. Ressaltaremos algumas conclusões advindas dele. 0 objetivo maior desse plano é interligar territorialmente o interior do estado de São Paulo, bem como ligá-lo a seus vizinhos por intermédio das vias de comunicação. A nosso ver, o que ele propõe é uma rede articulada dos meios de transporte e de comunicações: vias ferroviárias, fluviais e rodoviárias, e destas, com as linhas de telégrafos.

A opção pela interligação de São Paulo com o Mato Grosso via linha férrea Sorocabana, além de atender às necessidades técnicas e estar de acordo com uma solução racional e econômica, era a mais lucrativa para o desenvolvimento do Estado, pois, além de permitir a interligação territorial, esta ocorreria por dentro do estado de São Paulo, por área pouco ocupada e com imenso potencial de valorização, além de assegurar o escoamento da produção pelo porto de Santos.

O fim das Considerações feitas por Sampaio dialoga de forma contundente com os planos que nas últimas décadas se tem feito para a região. Recentemente, buscava-se estabelecer uma rede de infraestrutura ligando o estado de São Paulo a países da América Latina, a qual estava sendo concebida e projetada com esse fim, incluindo ferrovias (Novoeste e Ferronorte), hidrovia TiêteParaná (no Rio Paraná) e gasoduto (Bolívia-Brasil), passando pelo Vale do Paranapanema, além de cortar o estado de Mato Grosso do Sul [...]

[...] (www.antf.org.br ; www.transportes.sp.gov.br ; www.tbg.com.br).

(C) Labor \& Engenho, Campinas [SP] Brasil, v.11, n.3, p.280-295, jul./set. 2017. 
De certa forma, a possibilidade de São Paulo se inserir como cidade fundamental no território abrangido pelo Mercosul, e, em outro patamar, como uma cidade global, tem seus antecedentes no final do dezenove. As obras propostas por Theodoro Sampaio, ou, ao menos, sua discussão sugerida a partir de seu relato, teria contribuído para dar margens a ampla infraestruturação do estado e da capital paulistana no final do século XIX. Ao longo do século XX essa rede de infraestrutura só veio a se desenvolver ainda mais, sofrendo uma contínua ressignificação na sua razão de ser, bem como na sua extensão e complexidade, via de regra, motivada pela necessidade de se adaptar as novas demandas postas pela ininterrupta transformação dos modos de produção (em escala local, nacional e internacional), distribuição e consumo de mercadorias no contexto do desenvolvimento, crise e reconfiguração que o capitalismo passou ao longo do último século. Parece-nos claro que aí está um dos fatores que explicam os caminhos pelos quais ocorreram o grande acúmulo de capital e a fenomenal modernização porque São Paulo passou e passa.

Daí que, quando, aproximadamente, um século ${ }^{1}$ depois destas Considerações acerca o Vale do Paranapanema, assistimos a uma acerada disputa pela pose da terra capitaneada, sobretudo, pelo Movimento dos Sem Terra (MST) e proprietários de terras no Pontal do Paranapanema, nos perguntamos até que ponto esses conflitos não tem suas raízes históricas neste plano territorial então delineado por Theodoro Sampaio. Até que ponto sua recomendação de que as terras do Vale fossem "reservadas" e que se esperasse para só pô-las no mercado de terra e no ciclo produtivo quando as mesmas fossem lucrativas, não estão relacionadas com a existência dos grandes latifúndios (muitos dos quais, improdutivos) que, em última análise, oferecem o substrato para o campo de batalha pela posse da terra que a área vivenciou no crepúsculo do último século?

\section{0 início da ocupação do Pontal do Paranapanema}

O processo de ocupação e posse de terras no Brasil, anterior a 1850, já conta com um bom conjunto de estudos consistentes, bem como as razões e as implicações da promulgação da Lei de Terras deste mesmo ano, também já conta com seus estudos (Costa, 2003). Não os retomaremos aqui, pois a consideração analítica dos mesmos foge aos nossos intuitos imediatos. Entretanto, acreditamos ser necessário retomarmos, brevemente, alguns pontos referentes a esse emblemático ano, para melhor nos situarmos.

A partir de 1850 começam a ocorre uma série de mudanças na estrutura social brasileira (tanto no plano econômico, como político e social) que ocasiona uma significativa mudança no padrão de urbanização brasileiro até então observado. Inegavelmente, após o fim do tráfico negreiro, neste ano, uma série de fatores políticos e econômicos potencializou estas mudanças: a liberação de capitais investidos no "comércio infame" que migrou para o investimento em obras de infraestrutura urbana nas principais cidades do país,' Lei de Terras, abolição da escravidão, imigração, Proclamação da República e a ascensão do café como produto maior da produção e exportação nacional (Schwarcz, 1998).

Os rebatimentos da nova ordem social na configuração espacial do país foram: surgimento de uma "burguesia nacional"; uma maior estratificação social; desenvolvimento de certo mercado interno; criação de um mercado de trabalho; fomentação de um surto industrial e de um sistema de crédito (mais bem desenvolvido e consolidado); a apropriação e ocupação de terras em uma perspectiva capitalista; desenvolvimento de uma série de redes de infraestrutura das quais as ferrovias (interligando o território - ainda que em extensão limitada) conjuntamente com as redes de água e esgoto, bem como a remodelação dos portos, ocupam lugar de destaque; reestruturação do Estado em bases capitalistas apontando para uma maior racionalidade, eficiência e eficácia tipicamente burguesas, o que, sem dúvida, acabou por fortalecer o papel da cultura e da vida urbana no cenário social do país (Costa, 2003). Nessa nova dinâmica, "rompia-se a estreita autosuficiência do latifundiário, o que estimulava o comércio interno, permitindo uma relativa distribuição de riqueza" (Costa, 1987, p. 211). Conhecida como a "era de Mauá", esse período caracteriza-se por investimentos vultosos tanto na área financeira, como na industrial (Caldeira, 1995).

\footnotetext{
1 Referimo-nos à década de 1990, quando o conflito entre proprietários de terras no vale o MST atingiu o seu pico de visibilidade.
} 


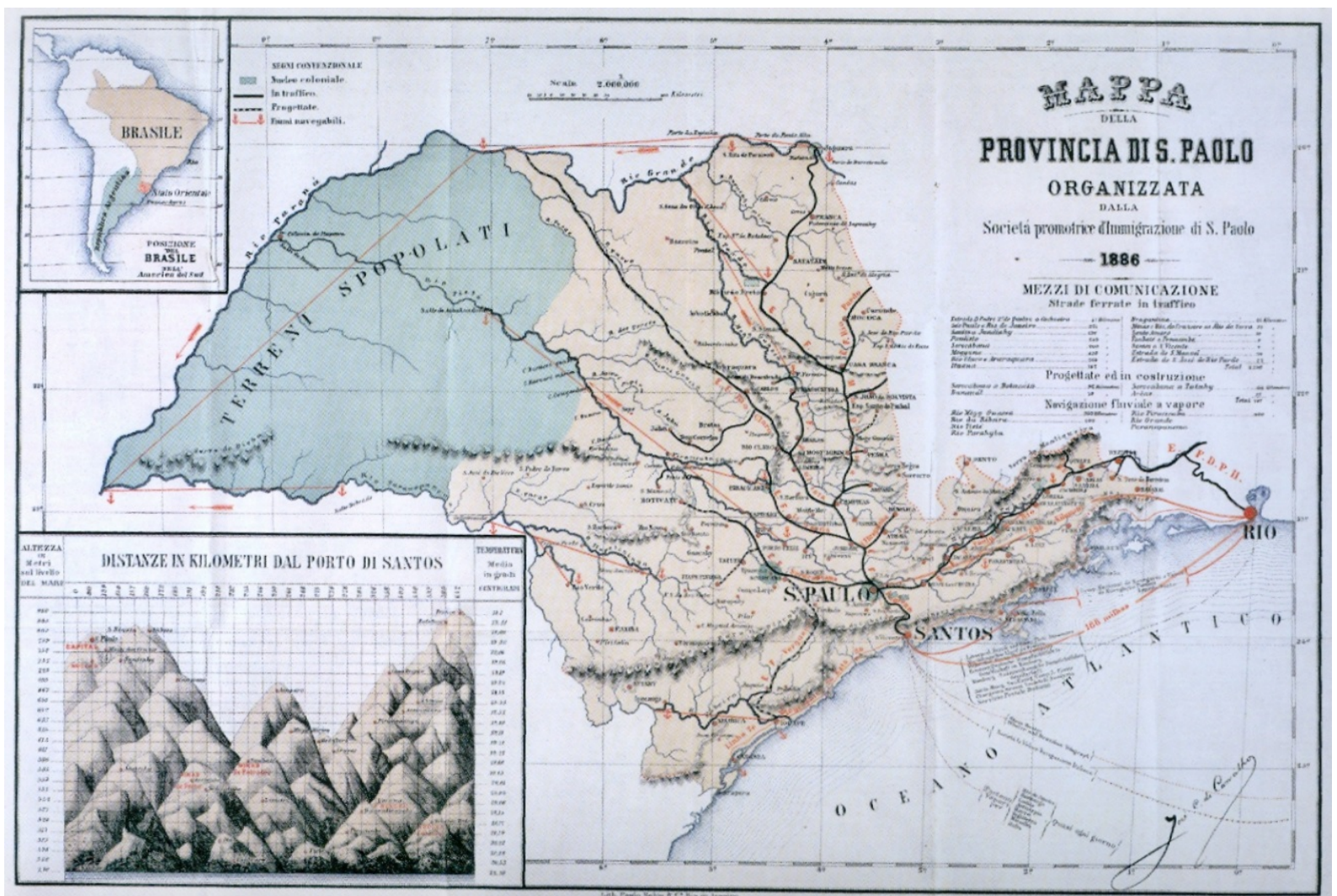

Figura 2. Mapa da Província de São Paulo organizada pela Sociedade Promotora da Imigração de são Paulo, 1886. Fonte: http://commons.wikimedia.org/wiki/File:Mappa_della_Provincia_di_S._Paolo.jpg

Note-se que o "extremo Oeste" paulista é descrito como despovoado. Ele será alvo da expansão cafeeira, o que levará a sua ocupação a partir de 1850. Grosso modo, a região do Pontal do Paranapanema é a confluência dos Rios Paraná e Paranapanema que, em 1886, ainda é descrita como "desocupada". Esse mapa é organizado pela Sociedade Promotora da Imigração de São Paulo.

No "oeste paulista" essa onda de transformação, chegou, quando muito, na forma de uma marola. É assim que, a despeito da promulgação da Lei de Terras, a qual, entre outras deliberações e implicações, proibia a aquisição de terras públicas através de qualquer outro meio que não fosse compra, se contrapondo, portanto à dinâmica do tempo pretérito, no qual a obtenção de terras se dava por meio de posses ou de doações feitas pela Coroa, na região em foco, nada mudou. A Lei era solenemente ignorada, o que quer dizer que foi baseado em processos ilegais os quais implicavam em invasões de terras, grilagem e falsificação de documentos probatórios da propriedade da terra, tudo untado em um contexto de violência e brutalidade, deferido contra o gentio, contra fauna e a flora local que se deu a ocupação deste vasto território. Nesse sentido, ver entre outros: Andrade, 2006; Leite, 1998; Leonidio, 2010.

A década de 1850, no Vale do Paranapanema, viu surgir ainda uma onda de interesse, por parte do governo estadual e de sua elite, por essas terras. Silvia Figueirôa (2008) aponta que data de 1855 as primeiras menções à ocupação racional-cientifica dessa região desconhecida. Para tal, cita um trabalho do geógrafo norte-americano Orville Derby de 1889, no qual ele aponta dados nessa direção. A partir de 1886 a Comissão Geografia e Geológica de São Paulo foi uma (talvez, a primeira) entre outras que buscou esquadriar a região ${ }^{2}$, ato contínuo, ocupá-la de forma mais racional, como visto anteriormente. Porém, a ocupação de fato começa naquele ano emblemático de 1850.

Reinaldo Viotto Ferraz Júnior (2005, p. 12) afirma que:

[...] o que conhecemos hoje como Pontal do Paranapanema, é parte integrante de uma antiga posse de terras chamada Fazenda Pirapó-Santo Anastácio, cuja história se liga à posse contígua ao norte, à Fazenda Boa Esperança do Aguapehy, as vezes também denominada como Boa Esperança do Água Pehy.

\footnotetext{
2 Podemos citar ainda a Comissão Rondon que chega a região por volta de 1911. Cobra, 1923.
} 
Essas terras ficavam para muito depois de Botucatu. Segundo consta, Botucatu, por volta de 1850, era a última Vila da então Província de São Paulo (Leonídio, 2007); para além dela, abria-se a imensidão do desconhecido "oeste paulista": território habitado, sobretudo, pelo gentil. Esse território, por assim dizer, aguardava por ser "civilizado", isto é, ocupado pelo homem "branco" de "descendência" europeia. O mais remotamente que se sabe acerca da presença do "homem branco" nessa região, remete aos Bandeirantes, entre os séculos XVII e XVIII, os quais teriam sido os primeiros a estarem aí. Buscavam então, índios para serem vendidos como escravos (Holanda, 1976).

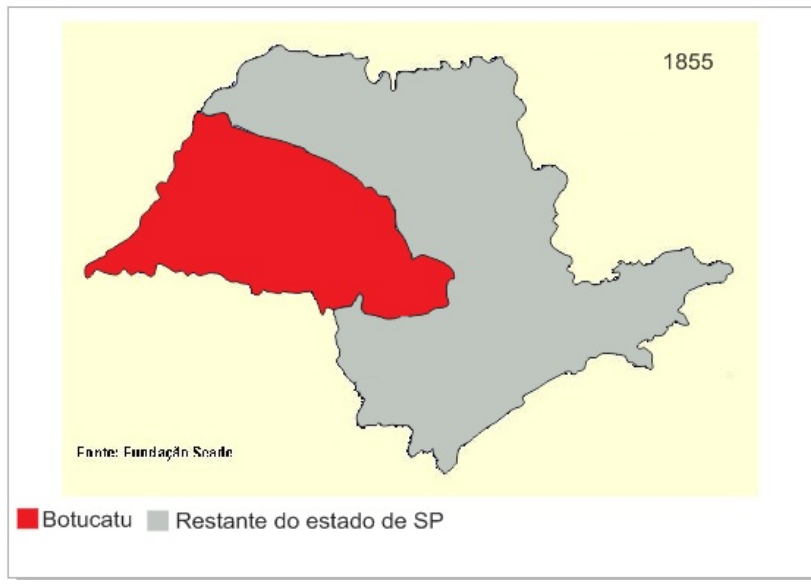

Figura 3. Mapa da Extensão do Território de Botucatu em 1855.

Fonte: Silva (2013). Note-se que o território de Botucatu (em vermelho) - à época, englobava toda a área que hoje denominamos Pontal do Paranapanema em sua maior parte, era tomado como "desconhecido" e ocupado, sobretudo, pelo gentio.

Esse território, que era ainda um grande "vazio" no meio do dezenove, começou a ser objeto de cobiça de posseiros e proprietários a partir de então. Autores como, Alessandro Soares da Silva (2010), Adalmir Leonidio (2007), José Ferrari Leite (1998), Pierre Monbeig (1984), Amador Nogueira Cobra (1923) entre outros, apontam José Teodoro de Souza e Antônio José de Gouveia como os primeiros forasteiros, egressos das Minas Gerais, a terem a posse de vastas glebas nessa região. 0 primeiro teria chegado por volta dessa época à localidade e, em 1856, fizera saber da existência de registro paroquial - lavrado na Vila de Botucatu pelo vigário Modesto Marques -, que lhe conferia a posse das terras que denominou de Fazenda Rio do Peixe (ou Fazenda Boa Esperança do Água Pehy). A referida gleba teria uma área de 872.200ha. 0 segundo, no mesmo ano, apresentou também um registo paroquial, este lavrado na Paroquia de São João Batista do Rio Verde (hoje, município de Itaporanga), pelo Frei Pacífico de Monte Falco, o qual dava posse a esse de vastas terras, as quais o mesmo passou a denominar de Fazenda Pirapó - Santo Anastácio. A área da gleba em questão era, segundo medidas da época, da ordem de 148.011 alqueires, isto é, hoje, aproximadamente 583.100ha. Ambos, à época, apenas registraram a posse, nunca providenciaram o título de legitimação.

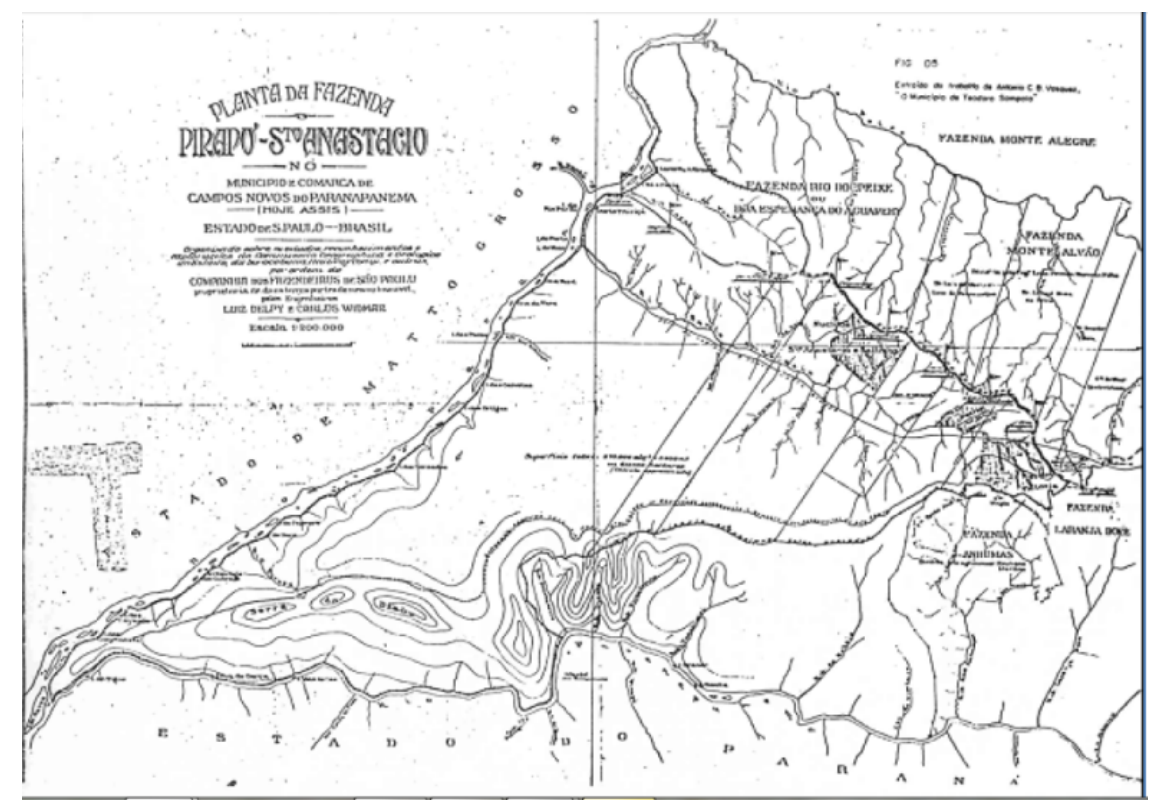

Figura 4. Planta da Fazenda Pirapó - Santo Anastácio. Fonte: Leite, 1998; Ministério do Desenvolvimento Agrário, 2011. 
O Processo de desmembramento desta vasta área tem início em 1865 quando de Botucatu originase o município Lençóis Paulista. De 1865 á 1876 ocorrem uma série de desmembramentos a partir desta cidade, cominando no surgimento dos municípios de Campos Novos Paulistas e de Conceição do Monte Alegre nesse ano. Deste último, em 1921, é desmembrada a cidade de Presidente Prudente que veio, ao longo do século XX, constituir-se como o principal município da Região. Grosso modo, todas as 32 cidades que compõem o Pontal do Paranapanema se originaram destas duas cidades.
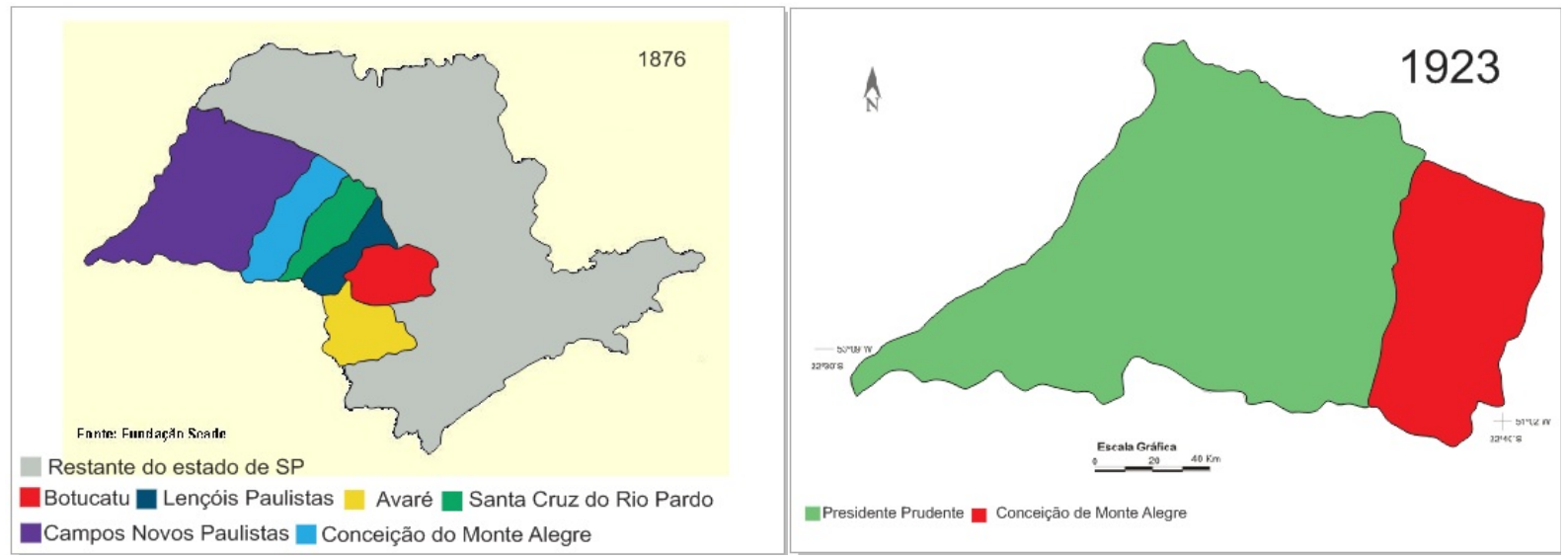

Figura 5. Mapas dos Desmembramentos do "Extremo Oeste" Paulista.

Fonte: Silva (2013). o primeiro mapa refere-se ao ano de 1876, quando forma-se o município de Campos Novos Paulista e Conceição de monte Alegre. O Segundo data de 1923 e mostra a área, grosso modo, do que hoje entendemos por Pontal do Paranapanema.

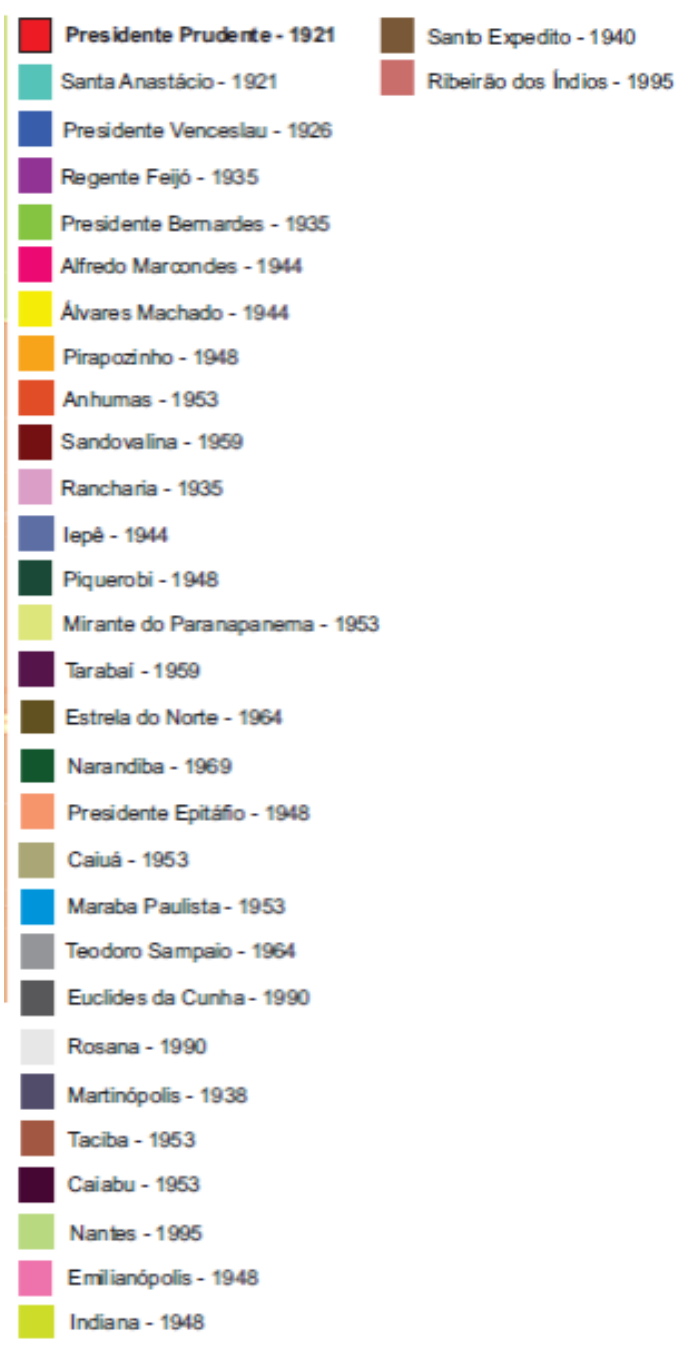

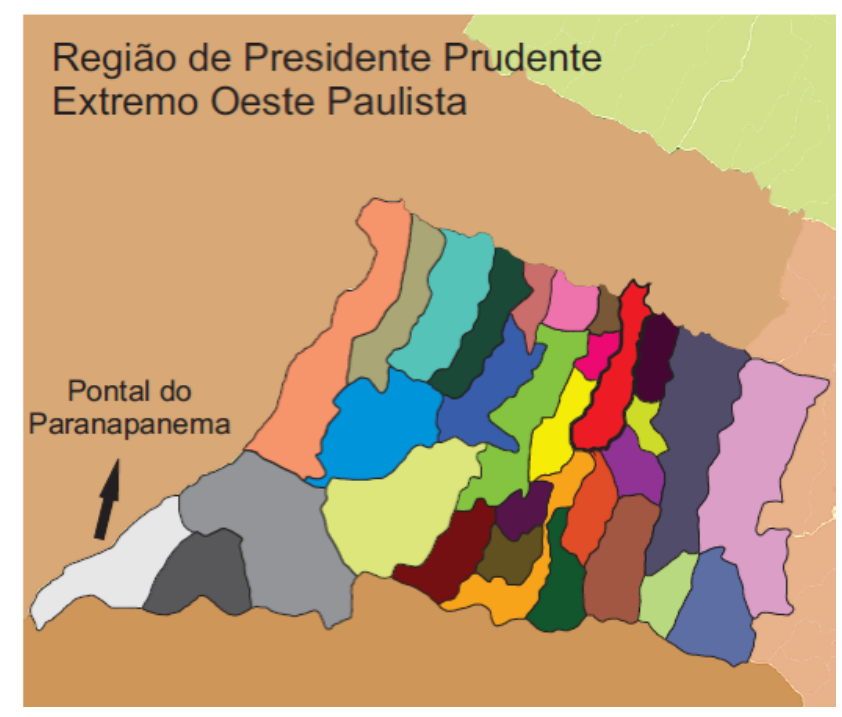

Figura 6. Mapa do Pontal do Paranapanema com sua divisão territorial

Fonte: Silva (2013).

O Pontal do Paranapanema, localizado no extremo oeste do estado de São Paulo, é uma região com $18.844,60 \mathrm{~km}^{2}$. Sua posição é estratégica (tanto para o estado, como para o país) considerando sua proximidade com os estados de Mato Grosso do Sul e Paraná, bem como devido à inserção do país no Mercosul, como anteriormente mencionado. Segundo os dados do IBGE (Censo de 2010) a população total desse território é de 583.703 habitantes, dos quais 89,74\% estão concentrados em áreas urbanas. A área tem ganhado notoriedade nacional dado os muitos 
conflitos sociais relativos à concentração de terras, envolvendo disputas entre movimentos populares, como por exemplo, o MST (Movimento dos Trabalhadores Rurais Sem-Terra), e os latifundiários e pela luta pela Reforma Agrária. 0 Pontal do Paranapanema caracteriza-se com uma das áreas mais carentes do estado paulista. A Tabela 1 apresenta o nome de seus 32 municípios, conjuntamente com os dados da data de sua fundação, extensão territorial, população total e percentagem da população urbana.

Tabela 1. Quadro de desmembramento territorial de São Paulo.

\begin{tabular}{|c|c|c|c|c|c|}
\hline & Nome da Cidade & $\begin{array}{c}\text { Data de } \\
\text { fundação }\end{array}$ & Área $\left(\mathrm{Km}^{2}\right)$ & $\begin{array}{c}\text { População } \\
\text { Total }\end{array}$ & $\begin{array}{c}\text { População } \\
\text { Urbana } \\
(\%)\end{array}$ \\
\hline 1 & Alfredo Marcondes & 1948 & 119,504 & 3.891 & 83,65 \\
\hline 2 & Álvares Machado & 1916 & 346,283 & 23.506 & 90,10 \\
\hline 3 & Anhumas & 1953 & 320,926 & 3.738 & 81,84 \\
\hline 4 & Caiuá & 1953 & 535,522 & 5.039 & 81,41 \\
\hline 5 & Caiabu & 1953 & 251,949 & 4.072 & 38,30 \\
\hline 6 & Emilianópolis & 1948 & 223,311 & 3.024 & 82,57 \\
\hline 7 & Estrela do Norte & 1953 & 263,273 & 2.661 & 78,99 \\
\hline 8 & Euclides da Cunha Paulista & 1965 & 577,122 & 9.585 & 63,76 \\
\hline 9 & Iepê & 1944 & 596,066 & 7.627 & 88,83 \\
\hline 10 & Indiana & 1948 & 127,597 & 4.828 & 85,45 \\
\hline 11 & João Ramalho & 1959 & 416,035 & 4.138 & 85,40 \\
\hline 12 & Marabá Paulista & 1954 & 917,119 & 4.812 & 44,51 \\
\hline 13 & Martinópolis & 1939 & $1.253,158$ & 24.260 & 84,00 \\
\hline 14 & Mirante do Paranapanema & 1953 & $1.237,847$ & 17.064 & 58,88 \\
\hline 15 & Nantes & 1995 & 285,415 & 2.707 & 89,80 \\
\hline 16 & Narandiba & 1964 & 358,139 & 4.289 & 72,39 \\
\hline 17 & Piquerobi & 1917 & 482,506 & 3.541 & 75,49 \\
\hline 18 & Pirapozinho & 1949 & 480,795 & 24.718 & 94,98 \\
\hline 19 & Presidente Bernardes & 1923 & 753,743 & 13.544 & 77,33 \\
\hline 20 & Presidente Epitácio & 1907 & 1281,779 & 53.352 & 93,29 \\
\hline 21 & Presidente Prudente & 1917 & 562,794 & 207.625 & 97,95 \\
\hline 22 & Presidente Venceslau & 1921 & 755,010 & 37.915 & 95,67 \\
\hline 23 & Rancharia & 1916 & $1.584,726$ & 28.773 & 89,67 \\
\hline 24 & Regente Feijó & 1922 & 265,087 & 18.496 & 92,17 \\
\hline 25 & Ribeirão dos Índios & 1995 & 196,991 & 2.187 & 84,59 \\
\hline 26 & Rosana & 1964 & 741,216 & 16.691 & 80,53 \\
\hline 27 & Sandovalina & 1958 & 455,393 & 3.699 & 69,76 \\
\hline
\end{tabular}




\begin{tabular}{|l|l|r|r|r|r|}
\hline 28 & Santo Anastácio & 1925 & 552,546 & 20.498 & 93,18 \\
\hline 29 & Santo Expedito & 1958 & 93,913 & 2.806 & 88,52 \\
\hline 30 & Taciba & 1935 & 608,310 & 5.714 & 84,91 \\
\hline 31 & Tarabaí & 1965 & 197,221 & 6.605 & 92,44 \\
\hline 32 & Teodoro Sampaio & 1952 & $1.556,670$ & 21.389 & 81,20 \\
\hline
\end{tabular}

Fonte: Quadro de desmembramento territorial de São Paulo, IBGE - Censo de 2010. Nota-se que os municípios mais recentes estão Ribeirão dos Índios e Nantes, ambos de 1995.

Concentrando $24 \%$ da população da RA, Presidente Prudente é ao mesmo tempo sua sede regional e seu maior polo. Situada na área de influência da Hidrovia Tietê-Paraná, a RA de Presidente Prudente tem entre suas principais vias de comunicação à ferrovia, que a liga a Santa Cruz de La Sierra, na Bolívia, e a Rodovia Raposo Tavares que a liga à capital. Suas principais atividades econômicas são a agropecuária e a agroindústria. Digno de nota é o serviço de produção e distribuição de eletricidade, gás e água da RA; cabe a ela a responsabilidade de originar cerca de $28 \%$ da energia hidráulica gerada em São Paulo.

Tendo em conta a tabela supracitada, a exceção da cidade de Caiabu, todas as demais tem mais de $50 \%$ das suas populações urbanas, sendo que muitas possui mais de $80 \%$ da população no meio urbano. Como defende Veiga (2002), "O Brasil é menos urbano que se calcula". Aqui cabe refletir sobre o sentido de urbano/urbanidade em uma região de fortes conflitos agrários.

\section{O MST e o Pontal do Paranapanema}

Segundo autores como Medeiros (2009) e Silva (2010) as raízes da questão da luta pelo acesso a terra no Brasil remete ao próprio processo de formação do país. Logo, para a compreensão da questão como na contemporaneidade se configura é necessário entender os processos históricos que caracterizam a sociedade brasileira desde o "achamento" da terra de Vera Cruz. Entretanto, foram ao longo dos últimos trinta anos que assistimos o recrudescimento da disputa pela posse de terras no Brasil. Isso tem se conformado nos constantes acampamentos e ocupações de terras verificadas em todo o país, tendo esse expediente sido por excelência a forma da luta pela terra empregada pelos agentes sociais que militam nesse sentido. Entre esses agentes destaca-se o papel exercido pelo Movimento dos Trabalhadores Rurais sem Terras - o MST. No Dizer de Medei$\operatorname{ros}(2009$, p.1): o MST $[\ldots]$

[...] tem marcado sua presença quer pela afirmação da importância da reforma agrária, quer pelo esforço de retirar esse tema dos quadros estritos do meio rural e da questão fundiária, mostrando suas articulações com opções políticas nacionais, projetos de nação e modelos de desenvolvimento". De fato, a questão da luta pela terra é um problema que transcende a questão do meio rural, estando ele diretamente relacionado com a cidade, de forma particular, e com o próprio processo de urbanização brasileira de uma forma mais ampla. Daí podermos afirmar que o MST constitui-se "como um importante agente da modernização da nossa sociedade (Medeiros, 2009).

As origens mais remotas do MST estão localizadas no ano de 1961 quando assume a Presidência da República o presidente João Goulart com a intenção de realizar amplas reformas de base as quais iriam alterar as relações econômicas e sociais no país, no que incluía a Reforma Agrária. 0 golpe militar de 1964 pôs fim a tais intuitos. Não obstante, o então presidente militar Marechal Castelo Branco decretou a primeira Lei de Reforma Agrária no Brasil: o Estatuto da Terra. No entender do MST (2009), tal lei foi elaborada "com uma visão progressista com a proposta de mexer na estrutura fundiária, ele jamais foi implantado e se configurou como um instrumento estratégico para controlar as lutas sociais e desarticular os conflitos por terra".

Entre 1965 e 1981 apenas oito desapropriações em média por ano ocorreram a despeito de terem ocorrido aproximadamente 70 conflitos por terra anualmente. De qualquer forma, ao longo dos 
anos de ditadura militar os movimentos sociais pela luta da terra foram crescendo e tomando forma. Data daí o começo das primeiras ocupações de terras organizadas, ainda que não tenham sido fruto de um movimento articulado. Tais ações estavam diretamente sob o influxo das alas progressistas da Igreja Católica a qual resistia à ditadura. Sendo assim, em 1975 há o surgimento da Comissão Pastoral da Terra (CPT). Segundo o MST (2009), a CPT [...]

[...] contribuiu para a organização das lutas camponesas, deixando de lado o viés messiânico, propondo para o camponês se organizar para resolver seus problemas [...]. Por isso o MST surgiu do trabalho pastoral das igrejas católica e luterana (MST, 2009).

Neste contexto, entre 20 e 22 de janeiro de 1984 na cidade de Cascavel foi realizado o Primeiro Encontro Nacional dos Sem Terra; essa reunião marca o ponto de partida da construção do MST. Nessa oportunidade se reuniram 80 trabalhadores rurais que ajudavam a organizar ocupações de terras em 12 estados do país. Os três estados do Sul do Brasil se constituíam então como o pólo político do movimento. Nos anos de 1990, o Movimento se expandiu para todo o país, tendo se consolidado como o principal porta-voz da luta pela terra. Contudo, foi aos pouco que o MST se estendeu por todo o país. Em São Paulo, é tomado como marco inicial da luta dos trabalhadores rurais "a luta dos posseiros da Fazenda Primavera nos municípios de Andradina, Castilho e Nova Independência para garantir sua permanência na Terra" ainda em 1920 (Silva, 2010, p.139).

De fato, a luta dos posseiros da Fazenda Primavera teve desdobramentos que se estenderam pelos anos seguintes. Tanto isso é verdade que nos anos de 1980 a referida fazenda volta a ser palco de conflitos de terras. Nesta década, segundo Sobreiro Filho (2012):

os conflitos na região tiveram como fator imprescindivel a intensificação dos interesses do capital associados à iniciativa do Estado no tocante à dotação de infra estrutura para benefícios do próprio capital. A construção das hidrelétricas de Porto Primavera, Rosana e Taquaruçu, prometeram promover o desenvolvimento, mas por fim resultou na demissão dos trabalhadores contratados, em enchentes nos rios e o reassentamento das famílias posseiras para áreas diante da inundação para a construção do reservatório da hidrelétrica (Sobreira Filho, 2012, p. 91).

Como se depreende desse trecho, mais uma vez vemos a associação dos interesses do capital com as iniciativas do Estado na produção do espaço construído do Pontal do Paranapanema. Aqui fica claro que essa região estava sendo objeto de planejamento por parte do Estado e que as obra de infraestruturação visavam a potencialização produtiva/lucrativa dessa área como sugerido por Theodoro Sampaio quase um século antes.

A década seguinte é marcada pela ação do MST na região organizando ocupação de terras no distrito de Primavera em Rosana. As famílias envolvidas nessa ação ocuparam a Fazenda Nova Pontal. Reivindicavam então [...]

[...] a suspensão da reintegração de posse, o sequestro da área ocupada devido ao conflito social, o adiamento do processo discriminatório das terras do Pontal do Paranapanema, o uso da violência e o assentamento imediato de 700 famílias (Sobreiro Filho, 2012, p. 94).

Daí em diante tanto os conflitos quanto o número de assentamentos foram crescendo. A tabela a seguir, apresenta o número de famílias assentadas em 2010, indicando as cidades onde os mesmos ocorreram assim como a área destes.

De acordo com os dados da Tabela 2, nota-se que a cidade de Mirante do Paranapanema foi onde o maior número de famílias foi assentado, em um total de 1625 , o que perfaz $26 \%$ do total de famílias assentadas; em segundo lugar, vem a cidade de Teodoro Sampaio com 856 famílias (14\%) e, em terceiro, a cidade de Rosana com 815 famílias (13\%). A soma das percentagens de famílias assentadas dessas três cidades perfaz $53 \%$ do total. Ao especializar esses números territorialmente, conforme indica o mapa a seguir, notamos que as três estão naquela área que segundo o 
Engenheiro Theodoro Sampaio havia sugerido que fossem "reservas de terras para o futuro". Isto é, todas estão localizadas nos "Campos". A rigor a exceção de Martinopolis que está nas "Matas" e, João Ramalho e Rancharia que estão localizadas nas terras altas, todas as demais se localizam nos "Campos". Caso curioso é o da cidade de Iepê que tem seu território nas três zonas estabelecidas pelo Engenheiro em questão. Dentro da argumentação desse trabalho, não à toa que as últimas cidades sejam aquelas que tiveram menos assentamentos no Pontal do Paranapanema.

Tabela 2. Assentamentos Rurais no Pontal do Paranapanema, segundo o número de Famílias, 2010.

\begin{tabular}{|l|r|r|}
\hline \multirow{2}{*}{ Municípios } & \multicolumn{2}{|l|}{ Número } \\
\cline { 2 - 3 } & $\begin{array}{l}\text { Famílias } \\
\text { assentadas }\end{array}$ & Área (ha) \\
\hline Caiuá & 445 & 10.732 \\
\hline Euclides da Cunha & 471 & 9.615 \\
\hline Iepê & 50 & 68 \\
\hline João Ramalho & 40 & 54 \\
\hline Marabá Paulista & 260 & 6.479 \\
\hline Martinópolis & 124 & 2.744 \\
\hline Mirante do Paranapanema & 1.625 & 34.984 \\
\hline Piquerobi & 84 & 2.594 \\
\hline Presidente Bernardes & 266 & 7.189 \\
\hline Presidente Epitácio & 342 & 7.533 \\
\hline Presidente Venceslau & 454 & 10.564 \\
\hline Rancharia & 178 & 4.264 \\
\hline Ribeirão dos Indios & 40 & 852 \\
\hline Rosana & 198 & 4.017 \\
\hline Sandovalina & 6.248 & 22.681 \\
\hline Teodoro Sampaio & 143.802 \\
\hline Total & & 19.432 \\
\hline
\end{tabular}

Fonte: Ministério de Desenvolvimento Agrário, 2011.

\section{Conclusão}

A primeira conclusão a que se chega do anteriormente exposto é que a ocupação da região chamada por Pontal do Paranapanema não se deu a esmo de um planejamento territorial articulado no seio do Estado e com a ativa participação da elite paulista. Pelo menos desde o fim do século XIX, a área vem sento objeto de um esquadrinhamento que busca potencializar seu território estratégico para o estado. Nesse sentido, o Plano elaborado pelo engenheiro Theodoro Sampaio desponta como marco desse longo processo de planejamento por que a área passou ao longo dos anos e hoje, ainda passa. 0 referido plano é surpreendentemente atual e como ele permite compreender os acontecimentos que aí tem palco. 


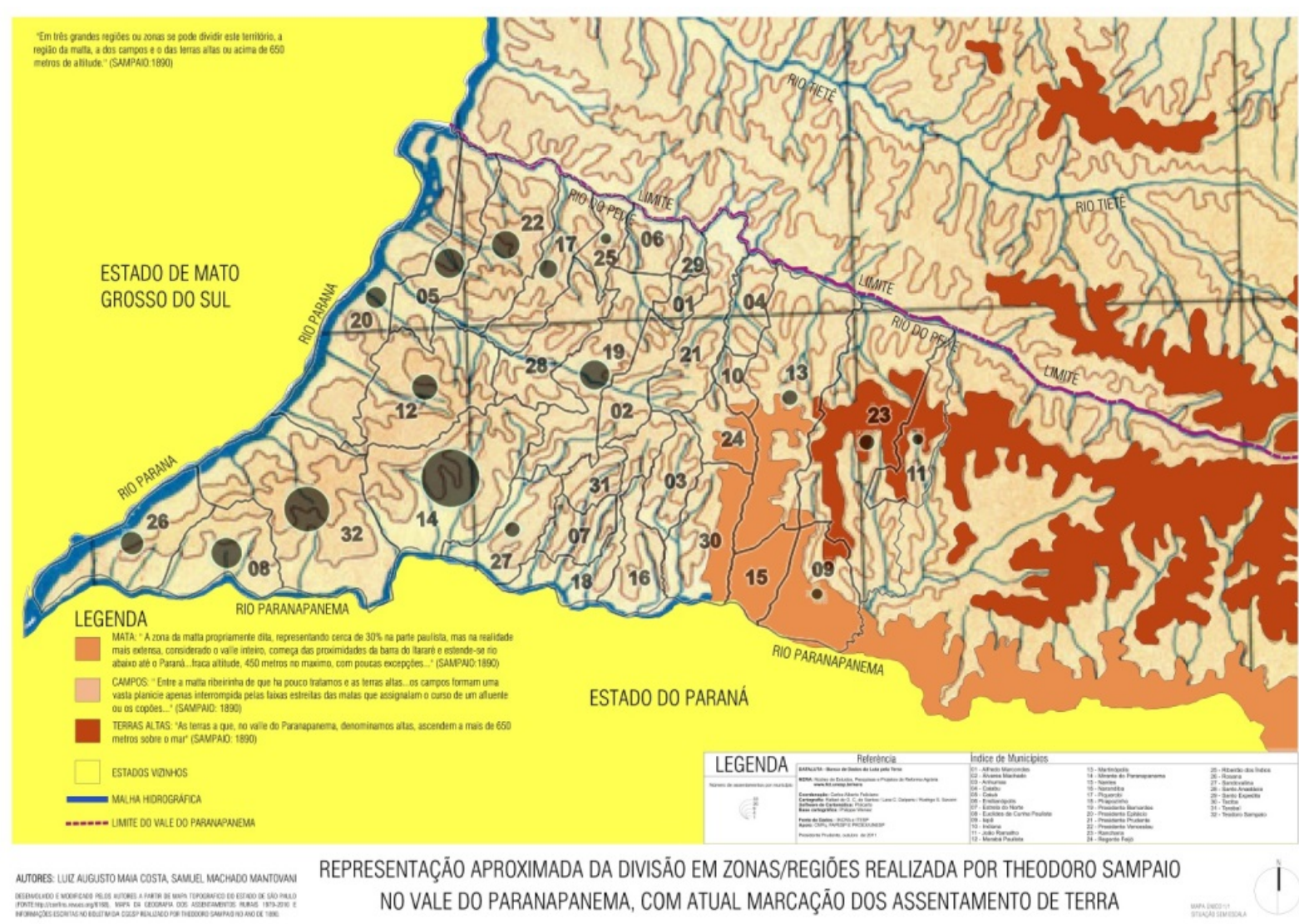

Figura 7. Mapa do Pontal do Paranapanema com a divisão de zonas propostas por Theodoro Sampaio, seus municípios e os assentamentos em 2011.

Fonte: Luiz Augusto Maia Costa e Samuel Machado Montovani.

Grosso modo, os 32 municípios que Compõem o pontal estão localizados na zona dos Campos, segundo divisão proposta por Theodoro Sampaio. O número 14 corresponde a cidade de Mirante do Paranapanema, já o número 32 refere-se a cidade de Teodoro Sampaio, e a cidade de Rosana é indicada pelo número 26.

Daí, chegamos à segunda conclusão desse artigo, se não há uma evidência conclusiva entre as recomendações de Sampaio sobre a "reserva futura" de terras na região e os conflitos de terras aí pressentes, podemos sim afirmar que esses conflitos têm suas raízes nos desdobramentos do tipo e do conteúdo dos projetos realizados (executados ou não) para o Pontal, os quais potencializaram a ocupação da região. As terras em disputas são aquelas identificadas como as que mais renderiam na região.

O que nos faz concluir que planejamento e conflitos por posses de terras no Pontal do Paranapanema estão intimamente ligados no processo de ocupação desse território

\section{Referências}

Andrade, P. P. (2006). Vale do Paranapanema: ocupação, especulação, devastação 1890-1944. Revista Eletrônica Patrimônio e Memória, 2 (1). Assis [SP]: CEDAP.

Caldeira, J. (1995). Mauá - Empresário do Império. São Paulo: Companhia das Letras.

Cobra, A. N. (1923). Em um recanto do sertão paulista. São Paulo: Hennies.

Costa, E. V. (1987). Da Monarquia à República: momentos decisivos. São Paulo: Editora Brasiliense S.A.

Costa, L. A. M. (2014). Nem Tudo Era Europeu: a presença norte-americana no debate de formação do urbanismo paulista (1886-1919). Santo André [SP]: Universidade Federal do ABC. 
Costa, L. A. M. (2003). O Ideário Urbano Paulista na Virada do Século: O Engenheiro Theodoro Sampaio e as Questões Territoriais e Urbanas Modernas em São Paulo (1886-1903). São Paulo: RiMa.

Costa, L.A.M; Montovani, S. M. (2013). Relatório Final de IC - 0 "extremo oeste paulista”, suas descrições científicas e a sua cartografia. 1850 - 2010. Campinas: CEATEC/PUC-Campinas.

Figueirôa, S. F. M. (2008). Batedores da ciência em território paulista: expedições do Sertão de São Paulo na transição para o século XX. História, ciências, saúde 15(3). Manguinhos [RJ] pp.763-777. Recuperado de: <http://www.scielo.br/pdf/hcsm/v15n3/10.pdf>.

Holanda, S. B. (1976) Monções. (2.ed.). São Paulo: Alfa-Omega.

Júnior Ferraz, R. V. (2005) Questão fundiária no Pontal do Paranapanema. Recuperado de <http:// intertemas.unitoledo.br/revista/index.php/Juridica/article/viewFile/361/355>.

Leite, J. F. (1998). A ocupação do Pontal do Paranapanema. São Paulo: Hucitec: Fundação UNESP.

Leonídio, A. (2007). Matar e desmatar. A ocupação inicial do Pontal do Paranapanema (1850-1930). In XXIV Simpósio Nacional de História - História e Multidisciplinaridade, São Leopoldo [RS]: Unisinos.

Leonídio, A. (2010). Raízes da violência rural no Brasil: Pontal do Paranapanema, 1990-2008. (Tese de Livre Docência), Universidade Estadual de São Paulo, São Paulo, SP.

Medeiros, L. S. (2009). A luta por terra no Brasil e o Movimento dos Trabalhadores Rurais sem Terra.

Recuperado de: <http://geopr1.planalto.gov.br/saei/images/publicacoes/2009/

nota_tecnica_a_luta_por_terra_no_brasil_e_o_movimento_dos.pdf $>$.

Ministério do Desenvolvimento Agrário (2011). Relatório Anual. Célula do Pontal do Paranapanema - SP. Acompanhamento e informação para o desenvolvimento rural. Recuperado de: <http://sit.mda.gov.br/ download/ra/ra073.pdf>.

Monbeig, P. (1984). Pioneiros e fazendeiros de São Paulo. São Paulo: Hucitec.

MST (2009). Os 25 anos do MST. Recuperado de: <www.mst.org.br/especiais/23>.

Oliveira, J. O. S. (1997). Contribuição ao estudo das origens da Ideologia do Planejamento Moderno no Brasil: Domingos Jaguaribe e as Propostas dos Núcleos coloniais 1874-1900 — Faces do Planejamento Territorial no Processo de Modernização sob o complexo Cafeeiro Paulista. (Tese de Doutorado). Universidade Estadual de São Paulo, Faculdade de Arquitetura e Urbanismo, São Paulo, SP, Brasil.

Sampaio, T. (1890). Boletim Noo 04 - Considerações Geográficas sobre o Vale do Rio Paranapanema. São Paulo: Comissão Geográfica e Geológica de São Paulo.

Sampaio, T. (1898). Terras de propriedade do Dr. Domingos Jaguaribe. São Paulo: Tipografia da Indústria de São Paulo.

São Paulo (Estado). (1995). Secretaria de Economia e Planejamento. Coordenadoria de Planejamento Regional. Instituto Geográfico e Cartográfico. Quadro do desmembramento territorial-administrativo dos municípios paulistas. São Paulo: IGC.

Schwarcz, L. M. (1998). As barbas do imperador: D. Pedro II, um monarca nos trópicos. São Paulo: Companhia das Letras.

Silva, A. S. (2010). O caminho da terra: revisitando a história do MST no Pontal do Paranapanema - SP desde uma ótica psicopolítica. Psicologia em Estudo. 15(1) Maringá, pp.137-149.

Silva, M. D. (2013). Relatório Final de IC: o Vale do Paranapanema, um lugar no extremo oeste paulista. 1850-2010. Campinas: CEATEC/PUC-Campinas. 
Sobreiro Filho, J. (2012). A luta pela terra no Pontal do Paranapanema: história e atualidade. Geografia em Questão, 5 (1). Recuperado de < http://e-revista.unioeste.br/index.php/geoemquestao/ article/download/4981/4939>.

Veiga, J. E. (2002). Cidades imaginárias. O Brasil é menos urbano do que se calcula. Campinas: Editora Autores Associados.

\subsection{Sites Acessados}

$<$ http://www.ibge.gov.br>.

$<w w w . a n t f$.org.br $>$.

$<w w w . t r a n s p o r t e s . s p . g o v . b r>$.

$<$ www.tbg.com.br>.

$<$ http://commons.wikimedia.org/wiki/File:Mappa_della_Provincia_di_S._Paolo.jpg>. 